\title{
Anti-tumor activity of fucoidan is mediated by nitric oxide released from macrophages
}

\author{
KAORI TAKEDA ${ }^{1,2^{*}}$, KOH TOMIMORI ${ }^{1,3^{*}}$, RYUICHIRO KIMURA $^{1,4^{*}}$, \\ CHIE ISHIKAWA ${ }^{1,4}$, TAMARA K. NOWLING ${ }^{5}$ and NAOKI MORI ${ }^{1}$
}

${ }^{1}$ Department of Microbiology and Oncology, Graduate School of Medicine, University of the Ryukyus, 207 Uehara, Nishihara, Okinawa 903-0215; ${ }^{2}$ Kanehide Bio Co., Ltd., 5-2-2 Nishizaki-cho, Itoman, Okinawa 901-0305; ${ }^{3}$ Department of Psychiatry, Naha City Hospital, 2-31-1 Furujima, Naha, Okinawa 902-8511; ${ }^{4}$ Transdisciplinary Research Organization for Subtropics and Island Studies, 1 Senbaru, Nishihara, Okinawa 903-0213, Japan; ${ }^{5}$ Department of Medicine, Division of Rheumatology, Medical University of South Carolina, 96 Jonathon Lucas Street, Ste 912 CSB, Charleston, SC 29425, USA

Received June 15, 2011; Accepted July 28, 2011

DOI: 10.3892/ijo.2011.1168

\begin{abstract}
Fucoidan, a sulfated polysaccharide, has significant cytotoxic activity against tumor cells; however, the mechanism(s) of this action remains poorly understood. The present study was designed to determine the in vitro and in vivo effects of fucoidan and their molecular mechanisms. Fucoidan from Cladosiphon okamuranus Tokida cultivated in Okinawa, Japan, delayed tumor growth in Sarcoma 180 (S-180)-bearing mice. However, it failed to inhibit S-180 cell growth in vitro. Activated macrophages are known to have anti-tumor effects. Murine RAW264.7 macrophages stimulated with fucoidan exerted cytotoxicity towards S-180 cells in vitro. This cytotoxicity was associated with nitric oxide (NO) production. Both cytocidal effect and NO production were significantly inhibited by L-NAME, an inhibitor of NO synthase (NOS). Furthermore, activation of nuclear factor- $\kappa \mathrm{B}$ was a key step in the transcriptional activation of the inducible NOS gene. Taken together, our results indicate that the anti-tumor activity of fucoidan on S-180 cells is mediated through increased NO production by fucoidan-stimulated macrophages via nuclear factor- $\mathrm{kB}$-dependent signaling pathway.
\end{abstract}

\section{Introduction}

Fucoidan is a complex sulfated polysaccharide found in the cell walls of several edible brown algae, including Fucus vesiculosus. The structure and composition of fucoidan vary among different brown seaweed species, but generally the compound consists primarily of L-fucose and sulfate, along with small quantities of

Correspondence to: Dr Naoki Mori, Department of Microbiology and Oncology, Graduate School of Medicine, University of the Ryukyus, 207 Uehara, Nishihara, Okinawa 903-0215, Japan

E-mail: naokimori50@gmail.com

*Contributed equally

Key words: fucoidan, sarcoma, macrophage, nitric oxide, inducible nitric oxide synthase, nuclear factor- $\kappa \mathrm{B}$
D-galactose, D-mannose, D-xylose and uronic acid (1). Previous studies have shown that fucoidan has significant biological activities, such as anti-bacterial (2), anti-viral (3), anti-coagulant (4), anti-oxidant (5), anti-inflammatory $(4,6)$ and immunomodulatory effects $(2,7)$. Other studies also described anti-carcinogenic properties (8-15). For example, in vitro studies demonstrated that fucoidan can inhibit cell proliferation and induce cell death in numerous cell lines, including human bile duct cancers (8), nonsmall-cell bronchopulmonary carcinoma (9) and lymphoma (10). It is also reported to inhibit the invasion of HT1080 human fibrosarcoma cells and the angiogenic activity of HeLa human uterine carcinoma cells (11). In vivo studies have also demonstrated that fucoidan is a potent anti-neoplastic compound; and is reported to suppress the growth of Ehrlich ascites carcinoma (12,13), Lewis lung carcinoma and B16 melanoma (14), and also inhibit the metastasis of 13762 MAT rat mammary adenocarcinoma (15).

We have examined the anti-tumor effect of fucoidan, which was purified from Cladosiphon okamuranus Tokida cultivated in Okinawa,Japan. Although fucoidan was effective in inhibiting the in vivo growth of implanted Sarcoma-180 (S-180) cells, it did not inhibit the growth of the same cells in vitro. Following activation by a variety of stimuli, it seems that interferon- $\gamma$ activates macrophages to induce tumor cytotoxicity (16). The present study was designed to further examine the cytotoxic effect of fucoidan. Specifically, we examined the effects of fucoidan on nitric oxide (NO) production in murine macrophages, and its related cytotoxic effect on S-180 cells in vitro.

\section{Materials and methods}

Reagents. The unsalted brown seaweed C. okamuranus Tokida was suspended in water, $0.57 \%(\mathrm{w} / \mathrm{vol})$ citric acid was added to the solution, and then heated at $90^{\circ} \mathrm{C}$ for $40 \mathrm{~min}$. The suspension was neutralized with $\mathrm{NaOH}$ and cooled at $40^{\circ} \mathrm{C}$. It was centrifuged at $3500 \mathrm{x}$ g by decantation centrifugal separator. The supernatant was collected, filtered by Cohlo filter, and concentrated by ultrafiltration (MW cutoff 6000). The extracts were dried by spraydrier. They were composed of carbohydrates (72\%), uronic acids $(24 \%)$ and sulfate $(8 \%)$. The amount of total carbohydrates was determined by the phenol- $\mathrm{H}_{2} \mathrm{SO}_{4}$ method using fucose as 
standard. Uronic acids were determined by the carbazole- $\mathrm{H}_{2} \mathrm{SO}_{4}$ method using D-glucuronic acid as the standard. Sulfate contents were measured by ion chromatography. The main carbohydrates were fucose. The content of fucoidan determined by highperformance liquid chromatography was $83 \%$ and MW was 21-kDa. Fucoidan was dissolved in phosphate-buffered saline at a concentration of $30 \mathrm{mg} / \mathrm{ml}$. Antibodies to p52 for Western blot analysis and nuclear factor- $\mathrm{KB}(\mathrm{NF}-\kappa \mathrm{B})$ subunits p65, p50, c-Rel and p52 for super shift assay were purchased from Santa Cruz Biotechnology (Santa Cruz,CA). Antibody to actin was purchased from NeoMarkers (Fremont, CA). Antibodies to iNOS, I $\mathrm{B} \alpha \alpha$, phospho-IкB $\alpha$ (Ser32 and Ser36), IкB kinase (IKK) $\alpha$, IKK $\beta$ and phospho IKK $\alpha$ (Ser180)/IKK $\beta$ (Ser181) were obtained from Cell Signaling Technology (Beverly, MA). $N$-acetyl-L-leucyl-Lleucyl-L-norleucinal (LLnL) and Bay 11-7082 were purchased from Sigma-Aldrich (St. Louis, MO) and Calbiochem (La Jolla, CA), respectively. $( \pm)-(E)$-4-ethyl-2-[(E)-hydroxyimino]-5-nitro3-hexenamide (NOR3) and $N^{G}$-nitro-L-arginine methyl ester hydrochloride (L-NAME) were from Dojindo Laboratories, Kumamoto, Japan.

In vivo therapeutic effect of fucoidan. $\mathrm{BALB} / \mathrm{c}$ strain athymic nu/nu mice were obtained from Ryukyu Biotec Co. (Urasoe, Japan). They were engrafted with $1 \times 10^{5} \mathrm{~S}-180$ cells by subcutaneous injection in the back region and then randomly placed into two groups of six mice each, one received vehicle only, while the other was treated with fucoidan. Treatment was initiated on the day of cell inoculation. Fucoidan was dissolved in distilled water at a concentration of $10 \mathrm{mg} / \mathrm{ml}$, and $100 \mathrm{mg} / \mathrm{kg}$ body weight of fucoidan was administered by oral gavage every day for 21 days. Control mice received the same volume of the vehicle only for 21 days. Tumor size was monitored once a week. All mice were sacrificed on day 21 , and then the tumors were dissected out and their weight was measured.

Cells. The mouse sarcoma cell line S-180 and macrophage cell line RAW264.7 were cultured in EMEM and Dulbecco's modified Eagle's medium (DMEM) supplemented with $10 \%$ heat-inactivated fetal bovine serum, respectively. To study the effects of factors released from macrophages on sarcoma cell growth, cultures were prepared in Transwell culture plates in which cells in the lower large compartment were separated from the cells in the upper small chamber by a semi-permeable membrane with a pore. S-180 cells were seeded in the bottom well and incubated for $24 \mathrm{~h}$. RAW264.7 cells were then added to the top chamber in the absence or presence of fucoidan, and the cultures thereafter incubated for a further $72 \mathrm{~h}$.

Assays for cell viability and apoptosis. S-180 cells were seeded on 96-well plates and cultured for $24 \mathrm{~h}$. Fucoidan was added at various concentrations and incubated for $72 \mathrm{~h}$. In addition, RAW264.7 cells and S-180 cells were cultured together in separate chambers for $72 \mathrm{~h}$. The viability of S-180 cells was evaluated by measuring the mitochondrial-dependent conversion of the water-soluble tetrazolium (WST)-8 (Nacalai Tesque, Kyoto, Japan) to a colored formazan product. After $72 \mathrm{~h}$ of culture, WST-8 $(5 \mu \mathrm{l})$ was added to each well in which S-180 cells were cultured for the last $4 \mathrm{~h}$ of incubation. Absorbance at $450 \mathrm{~nm}$ was measured using an automated microplate reader. The viability in untreated control cultures was considered $100 \%$, and all treated groups were compared relative to this value. Apoptotic events in cells were detected by staining with Annexin-V-Fluos (Roche Diagnostics, Mannheim, Germany) according to instructions provided by the manufacturer, and analyzed by flow cytometry (FACSCalibur, Becton-Dickinson, San Jose, CA).

Analysis of cell cycle. Cell cycle analysis was performed with the Cycletest Plus DNA reagent kit (Becton-Dickinson Immunocytometry Systems). Cell suspensions were analyzed on flow cytometry using Cell-Quest. The population of cells in each cell cycle phase was determined with the ModiFit software.

Measurement of NO. Nitrite, the stable end product of NO was measured by a colorimetric assay. Briefly, the medium was removed from individual wells and treated with Griess reagent ( $1 \%$ sulphanilamide and $0.1 \%$ naphtylethylene diamine dihydrochloride in $2 \% \mathrm{H}_{3} \mathrm{PO}_{4}$ ) for $10 \mathrm{~min}$ at room temperature. The optical density of the samples was obtained using an automated microplate reader at $550 \mathrm{~nm}$. A standard curve using a standard solution of $\mathrm{NaNO}_{2}$ in culture medium was employed to calculate the nitrite concentration.

Western blot analysis. Cells were lysed in a buffer containing $62.5 \mathrm{mM}$ Tris- $\mathrm{HCl}$ (pH 6.8), $2 \%$ sodium dodecyl sulphate, $10 \%$ glycerol, 6\% 2-mercaptoethanol and $0.01 \%$ bromophenol blue. Equal amounts of protein $(20 \mu \mathrm{g})$ were subjected to electrophoresis on sodium dodecyl sulphate-polyacrylamide gels followed by transfer onto a polyvinylidene difluoride membrane and probing with the specific antibodies. The bands were visualized with the enhanced chemiluminescence kit (Amersham Biosciences, Piscataway, NJ).

Reverse transcriptase-PCR (RT-PCR). Total cellular RNA from cells was extracted with TRIzol (Invitrogen, Carlsbad, CA) according to the protocol provided by the manufacturer. Firststrand cDNA was synthesized from $1 \mu \mathrm{g}$ total cellular RNA using an RNA-PCR kit (Takara Bio Inc., Otsu, Japan) with random primers. The primers used were 5'-TCATTGTACTCTG AGGGCTGACACA-3' (forward) and 5'-GCCTTCAACAC CAAGGTTGTCTGCA-3' (reverse) for murine inducible NO synthase (iNOS), and 5'-GTGGGGCGCCCCAGGCACCA-3' (forward) and 5'-CTCCTTAATGTCACGCACGATTTC-3' (reverse) for $\beta$-actin. The length of RT-PCR was 30 cycles. The PCR products were fractionated on $2 \%$ agarose gels and visualized by ethidium bromide staining.

Transfection and luciferase assay. The IкB $\alpha \Delta \mathrm{N}$-dominant-negative mutant is an I $\mathrm{K} \mathrm{B} \alpha$ deletion mutant lacking the $\mathrm{N}$-terminal 36 amino acids (17). The dominant-negative mutants of IKK $\alpha$, $\operatorname{IKK} \alpha(\mathrm{K} 44 \mathrm{M}), \operatorname{IKK} \beta, \operatorname{IKK} \beta(\mathrm{K} 44 \mathrm{~A}), \operatorname{IKK} \gamma$, IKK $\gamma(1-305)$ and NF- $\kappa B$-inducing kinase (NIK), NIK (KK429/430AA) have been described previously $(18,19)$. pGL3 iNOS plasmid was generated by inserting the murine iNOS promoter region $(-1588$ to +161 bp surrounding the transcription start site) into the pGL3-basic vector (Promega, Madison, WI) (20). Three internal deletion mutants, pGL3 iNOS $\kappa$ B2-, pGL3 iNOS $\kappa$ B1- and pGL3 iNOS $\kappa \mathrm{B} 1 / \kappa \mathrm{\kappa} 2-$, were constructed by deletion of two NF- $\kappa \mathrm{B}$ sites defined as the $\kappa B 1(-85$ to -76$)$ and $\kappa B 2$ ( -971 to -962$)$. RAW264.7 cells were plated on a plate and transfected with the appropriate reporter and effector plasmids using Lipofectamine 

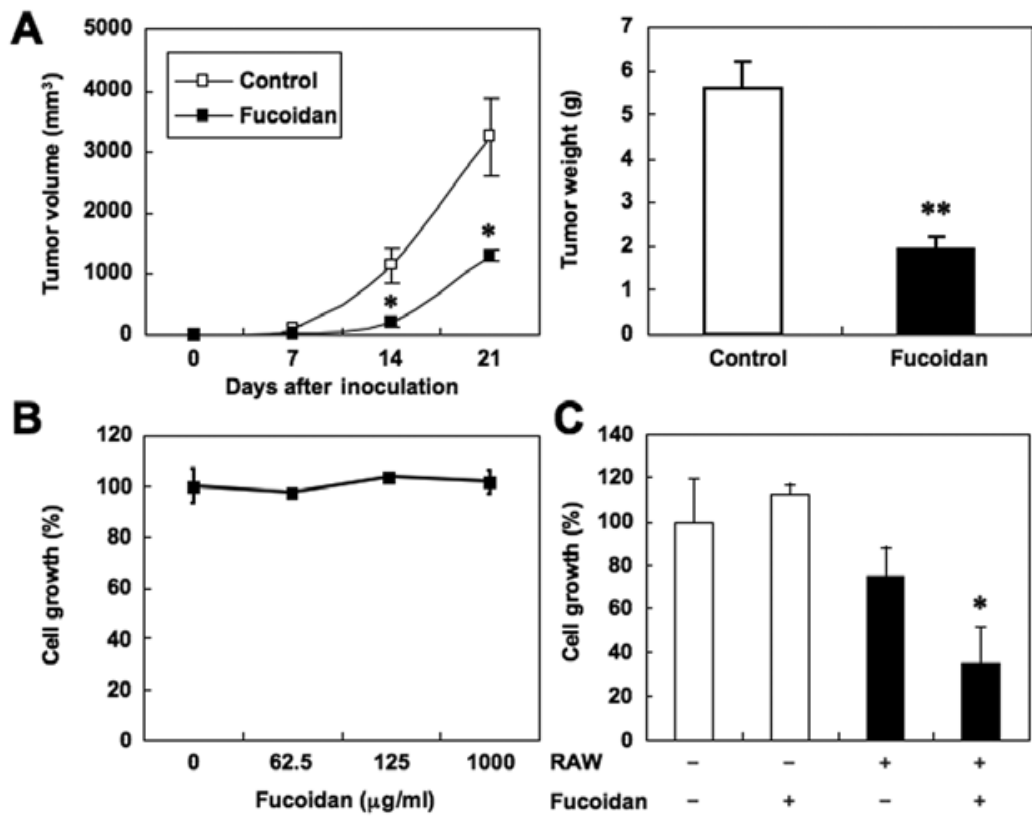

Figure 1. In vivo and in vitro anti-tumor activities of fucoidan on S-180 cells. (A) Inhibition of growth of S-180 cells in nude mice. Growth of the tumors after inoculation of S-180 cells subcutaneously (left panel) and weight of tumors removed from fucoidan-treated mice and untreated mice on day 21 after cell inoculation (right panel). Note the growth-suppressive effect of fucoidan. Data are mean $\pm \mathrm{SD}$ of six mice in each group. ${ }^{*} \mathrm{P}<0.005$, ${ }^{* *} \mathrm{P}<0.001$, compared with the control. (B) Fucoidan does not have any anti-tumor activity on S-180 cells by itself. S-180 cells were cultured with the indicated concentrations of fucoidan for $72 \mathrm{~h}$, and cell growth was determined in triplicate cultures by WST-8 assay. Data are mean \pm SD of triplicate cultures. (C) Anti-tumor effect of fucoidan-stimulated RAW264.7 cells against S-180 cells, measured by WST-8 assay. S-180 cells were grown for $72 \mathrm{~h}$ in the lower part of the Transwell chamber in the presence or absence of the RAW264.7 cells, which were placed on a microporous insert of a Transwell in the presence or absence of fucoidan $(250 \mu \mathrm{g} / \mathrm{ml})$. Thereafter, the upper chamber was removed and WST-8 was added to the lower compartment. Cell growth in untreated control cultures was considered $100 \%$. Data are mean \pm SD values of three experiments expressed as percentage of the control. ${ }^{*} \mathrm{P}<0.05$, compared with the control.

reagent (Invitrogen) according to the protocol supplied by the manufacturer. After 18-20 h, fucoidan was added and incubated for $6 \mathrm{~h}$. The cells were washed in phosphate buffered saline and lysed in reporter lysis buffer (Promega). Lysates were assayed for reporter gene activity with the dual-luciferase assay system (Promega). Luciferase activities were normalized relative to the Renilla luciferase activity from phRL-TK.

Electrophoretic mobility shift assay (EMSA). Nuclear extracts were obtained as described by Antalis and Goldbolt (21) with modifications, and EMSA was performed as described previously (22). Briefly, $5 \mu \mathrm{g}$ of nuclear extract was incubated with ${ }^{32} \mathrm{P}$-labeled probes. The DNA-protein complex was separated from the free oligonucleotides on $4 \%$ polyacrylamide gel. The probes used were prepared by annealing the sense and antisense synthetic oligonucleotides; a $\kappa \mathrm{B} 1$ site from the murine iNOS gene (5'-tcgaCCAACTGGGGACTCTCCCTTTGGGAA-3'), a $\kappa \mathrm{B} 2$ site from the murine iNOS gene (5'-tcgaTGCTAGGGGGA TTTTCCCTCTCTCTG-3') and an AP-1 element of the IL-8 gene (5'-gatcGTGATGACTCAGGTT-3'). The above underlined sequences represent the NF- $\mathrm{NB}$ or AP-1 binding site.

Statistical analysis. Data are expressed as the mean \pm SD. Differences between groups were assessed for statistical significance by the Student's t-test and Mann-Whitney U test as appropriate. $\mathrm{P}<0.05$ denotes the presence of a statistically significant difference.

\section{Results}

Effects of fucoidan in nude mice inoculated with $S$-180 cells. To explore the role of fucoidan on tumor growth in nude mice transplanted with murine S-180, we treated tumor-bearing mice with $100 \mathrm{mg} / \mathrm{kg}$ of fucoidan. After 21-day treatment, the mean tumor volume (Fig. 1A, left panel) and weight (Fig. 1A, right panel) were significantly lower than those of vehicle-treated mice. There was no significant difference in body weight gain during the period from day 0 to day 21 between the vehicle and fucoidan-treated groups (data not shown). During this period, mice treated with fucoidan appeared generally healthy. These results suggest that fucoidan has in vivo anti-tumor effect.

Inhibition of $S-180$ cell growth in vitro in the presence offucoidan and RAW264.7 cells but not by fucoidan alone. To study the mechanism of the anti-tumor effect of fucoidan, we determined the effects of fucoidan on cell growth of S-180 cells in vitro. Cell growth was assessed by the WST- 8 assay. Incubation with fucoidan alone at concentrations up to $1000 \mu \mathrm{g} / \mathrm{ml}$ for $72 \mathrm{~h}$ did not affect cell growth (Fig. 1B).

Activation of macrophages by agents such as bacterial lipopolysaccharide (LPS) stimulates their growth inhibitory effects on a wide variety of tumor cells (23). Based on this property, we next investigated the effects of macrophages on S-180 cells. RAW264.7 cells and S-180 cells were incubated together in different chambers separated by a semipermeable membrane, 

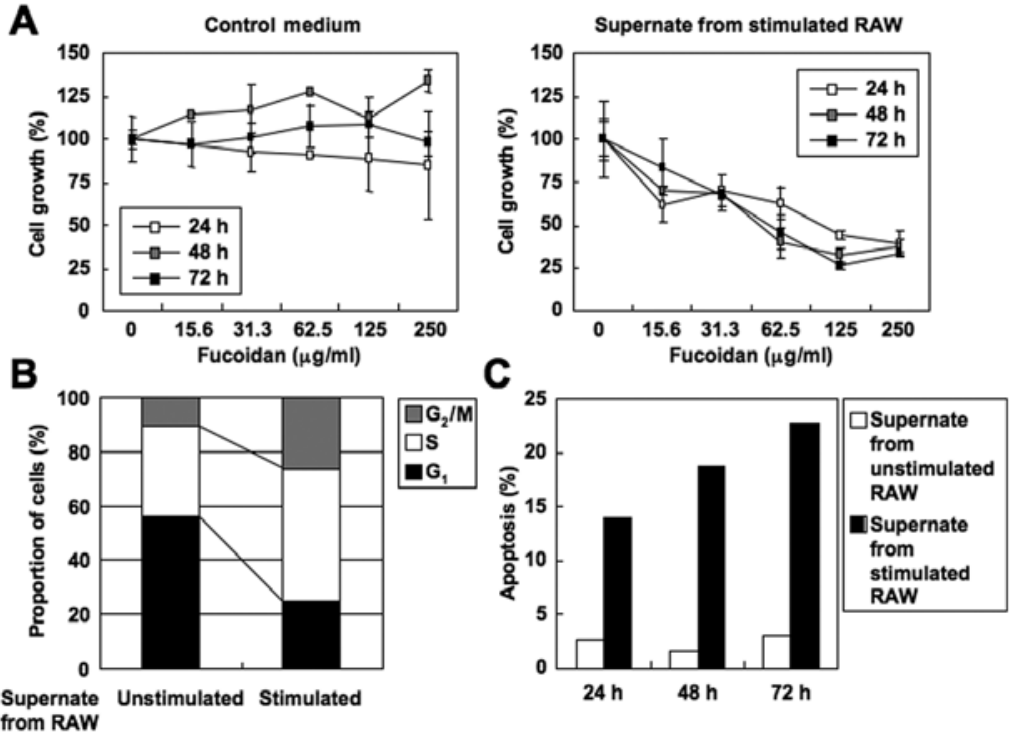

Figure 2. Anti-tumor effect of supernatants from fucoidan-stimulated RAW264.7 cells on S-180 cells. (A) Anti-tumor effect of supernatants from fucoidanstimulated RAW264.7 cells against S-180 cells, measured by WST-8 assay. RAW264.7 cells were cultured with various concentrations of fucoidan for 24,48 or $72 \mathrm{~h}$. The control samples did not include RAW264.7 cells. At the end of each incubation period, the supernatant was collected. S-180 cells were precultured for $24 \mathrm{~h}$. Thereafter, the culture media were removed and replaced by supernatants from fucoidan-stimulated RAW264.7 cells (right panel) or by the control medium (left panel). S-180 cells were incubated for another $72 \mathrm{~h}$, and cell growth was determined in triplicate cultures by WST-8 assay. Cell growth in control cultures [control medium in the absence of fucoidan (left panel) or supernatants from unstimulated RAW264.7 cells (right panel)] was scaled to present 100\%. Data are mean \pm SD values expressed as percentage of the control. (B) The supernatants from RAW264.7 cells stimulated with fucoidan induce $S$ and $\mathrm{G}_{2} / \mathrm{M}$ cell cycle arrest in S-180. S-180 cells were incubated for $24 \mathrm{~h}$ in the supernatants from RAW264.7 cells cultured for $72 \mathrm{~h}$ with or without fucoidan $(250 \mu \mathrm{g} / \mathrm{ml})$. Cell cycle distribution was analyzed by flow cytometry after staining with propidium iodide. (C) The supernatants from fucoidan-stimulated RAW264.7 cells induce apoptosis of S-180 cells. S-180 cells were incubated for 24,48 or $72 \mathrm{~h}$ in the supernatants from RAW264.7 cells cultured for $72 \mathrm{~h}$ with or without fucoidan $(250 \mu \mathrm{g} / \mathrm{ml})$. At the end of each incubation period, Annexin-V staining was analyzed by flow cytometry.

with or without fucoidan. Fucoidan did not exert any growth inhibitory activity on S-180 cells by itself, similar to the data shown in Fig. 1B, but it inhibited cell growth when cocultured with RAW264.7 cells (Fig. 1C).

S-180 cells were also cultured in the supernatants from RAW264.7 cells that had been stimulated with various concentrations of fucoidan. The supernatants suppressed cell growth of S-180 cells in a fucoidan dose- and time-dependent manner, while fucoidan-containing control medium had no growth inhibitory activity on S-180 cells (Fig. 2A). Thus, the RAW264.7associated inhibition of S-180 cell growth during in vitro culture seems to depend on crosstalk between the two cell populations.

Supernatant from fucoidan-stimulated RAW264.7 cells causes cell cycle arrest and apoptosis. To gain insight into the mechanism of the cell growth inhibitory effects of RAW264.7 supernatants, we used flow cytometry to examine the cellular DNA contents distribution in S-180 cells incubated for $24 \mathrm{~h}$ with supernatants from fucoidan-stimulated RAW264.7 cells or with supernatants from unstimulated RAW264.7 cells (control) (Fig. 2B). The supernatant from fucoidan-stimulated RAW264.7 cells increased the population of S-180 cells in the $S$ and $\mathrm{G}_{2} / \mathrm{M}$ phases, and markedly reduced cells in the $\mathrm{G}_{1}$ phase, relative cells incubated with the control. These results indicate that the supernatant from fucoidan-stimulated RAW264.7 cells induces $\mathrm{S}$ and $\mathrm{G}_{2} / \mathrm{M}$ arrest in S-180 cells. To further characterize the cytotoxicity of fucoidan-stimulated RAW264.7 supernatants against S-180 cells, we next analyzed the proportion of apoptotic cells by the Annexin- $\mathrm{V}$ method. In this assay, annexin- $\mathrm{V}$ binds to the cells that express phosphatidylserine on the outer layer of the cell membrane, a characteristic feature of cells entering apoptosis (24). Treatment with supernatant from fucoidanstimulated RAW264.7 cells increased, in a time-dependent manner, the proportion of cells positive for Annexin-V in S-180 cells, relative to cells treated with the control supernatant (Fig. 2C). These results indicate that, in addition to the induction of cell cycle arrest, the supernatant of fucoidan-stimulated RAW264.7 induces apoptosis of S-180 cells.

Fucoidan induces NO production and expression of iNOS mRNA and protein in RAW264.7 cells. Previous studies demonstrated the crucial role of NO in the tumoricidal activity of murine macrophages (25). Therefore, we examined the effects of fucoidan on NO production by RAW264.7 cells and the related anti-tumor effect on S-180 cells in vitro. NO production upon stimulation of RAW264.7 cells was assessed by measuring nitrite in the culture medium. Fucoidan stimulated the production of nitrite from RAW264.7 cells in a dose- and time-dependent manner (Fig. 3A).

NO is synthesized by NOS-catalyzed conversion of Larginine to L-citrulline. Whereas the activity of neuronal and endothelial NOS is mainly regulated post-translationally by cytoplasmic calcium levels or by phosphorylation by various protein kinases, iNOS is primarily regulated at the transcriptional level (26). To determine whether fucoidan-induced NO production from RAW264.7 cells was catalyzed by iNOS, we measured the iNOS level. When $250 \mu \mathrm{g} / \mathrm{ml}$ fucoidan was added to RAW264.7 cells, iNOS mRNA was detected from $3 \mathrm{~h}$ after treatment (Fig. 3B, bottom panels). When RAW264.7 cells were incubated with fucoidan for $6 \mathrm{~h}$, fucoidan induced iNOS 

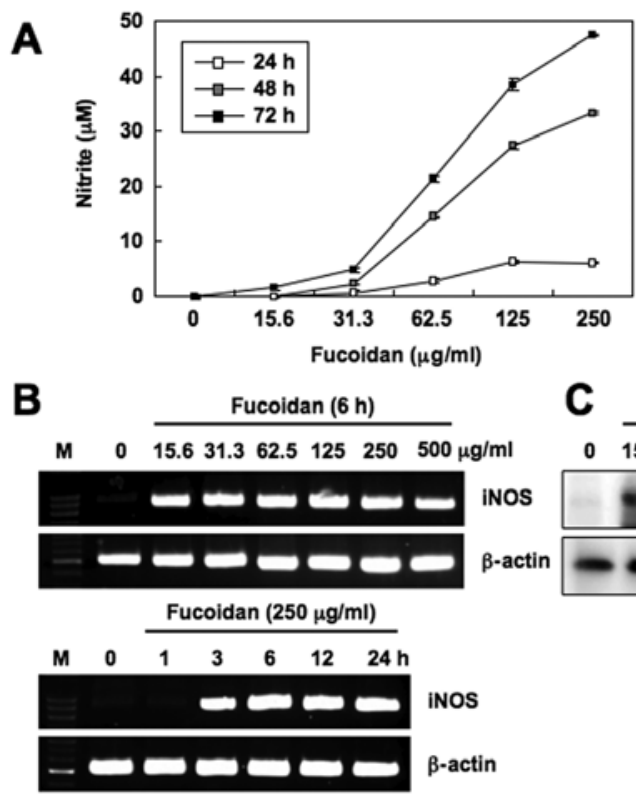

Figure 3. Effects of fucoidan on NO production and the expression of iNOS mRNA and protein in RAW264.7 cells. (A) RAW264.7 cells were incubated with various concentrations of fucoidan for the indicated time periods. NO production was determined by measuring the accumulation of nitrite in the culture medium. Data are mean \pm SD of triplicate cultures. (B) RAW264.7 cells were cultured with various concentrations of fucoidan (top panels) for $6 \mathrm{~h}$ or with fucoidan (250 $\mu \mathrm{g} / \mathrm{ml}$ ) for the indicated time periods (bottom panels). iNOS mRNA expression was detected by RT-PCR. (C) Effect of fucoidan on iNOS protein expression in RAW264.7 cells. RAW264.7 cells were incubated in a medium containing various concentrations of fucoidan for $24 \mathrm{~h}$ and iNOS protein levels were monitored in the cell lysates.
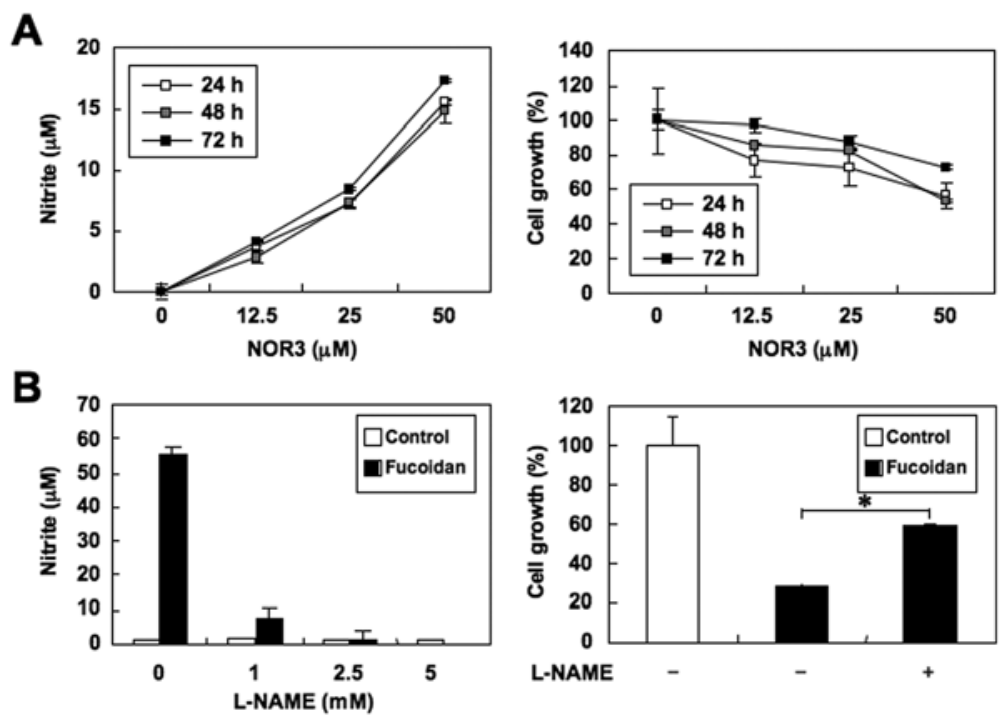

Figure 4. Near relationship between the concentration of nitrite and inhibition of S-180 cell growth. (A) Culture of S-180 cells in the presence of NOR3 results in a near relationship between nitrite concentration and cell growth inhibition. S-180 cells were cultured with various concentrations of NOR3 for 24,48 or $72 \mathrm{~h}$ The concentration of nitrite in the culture medium (left panel) and the relative cell growth of S-180 cells (right panel) were determined. (B) Nitrite formation in the culture medium and relative cell growth of S-180 cells in cocultures of fucoidan-stimulated RAW264.7 cells and S-180 cells in the presence of L-NAME. RAW264.7 cells were cultured with or without fucoidan $(250 \mu \mathrm{g} / \mathrm{ml})$ in the presence of $0,1,2.5$ or $5 \mathrm{mM} \mathrm{L-NAME}$ for $72 \mathrm{~h}$ (left panel). The concentration of nitrite in the culture medium was determined. S-180 cells were cultured in the presence or absence of fucoidan $(250 \mu \mathrm{g} / \mathrm{ml})$ and L-NAME $(1 \mathrm{mM})$ together with RAW264.7 cells separated by a semipermeable membrane for $72 \mathrm{~h}$ (right panel). The relative cell growth of S- 180 was determined by WST- 8 assay. Data are mean \pm SD of triplicate cultures. ${ }^{*} \mathrm{P}<0.001$, compared with the growth of S-180 cells cocultured with fucoidan-stimulated RAW264.7 cells in the absence of L-NAME.

mRNA expression at $15.6 \mu \mathrm{g} / \mathrm{ml}$ (Fig. 3B, top panels). The results also confirmed that $15.6 \mu \mathrm{g} / \mathrm{ml}$ fucoidan significantly increased iNOS protein level in RAW264.7 cells (Fig. 3C). These results suggest that the fucoidan-induced increase in NO production in RAW264.7 cells is mediated by the induction of iNOS expression.
In vitro anti-tumor effect of fucoidan-stimulated RAW264.7 cells on $\mathrm{S}-180$ cells involves $N O$. To evaluate the effect of $\mathrm{NO}$ on S-180 cells, we added exogenous NO donor, NOR3, to the culture medium of S-180 cells. The cells were cultured in the presence of different concentrations of NOR3 for 24-72 h and assessed by WST- 8 assay. Accumulation of nitrite in the medium 


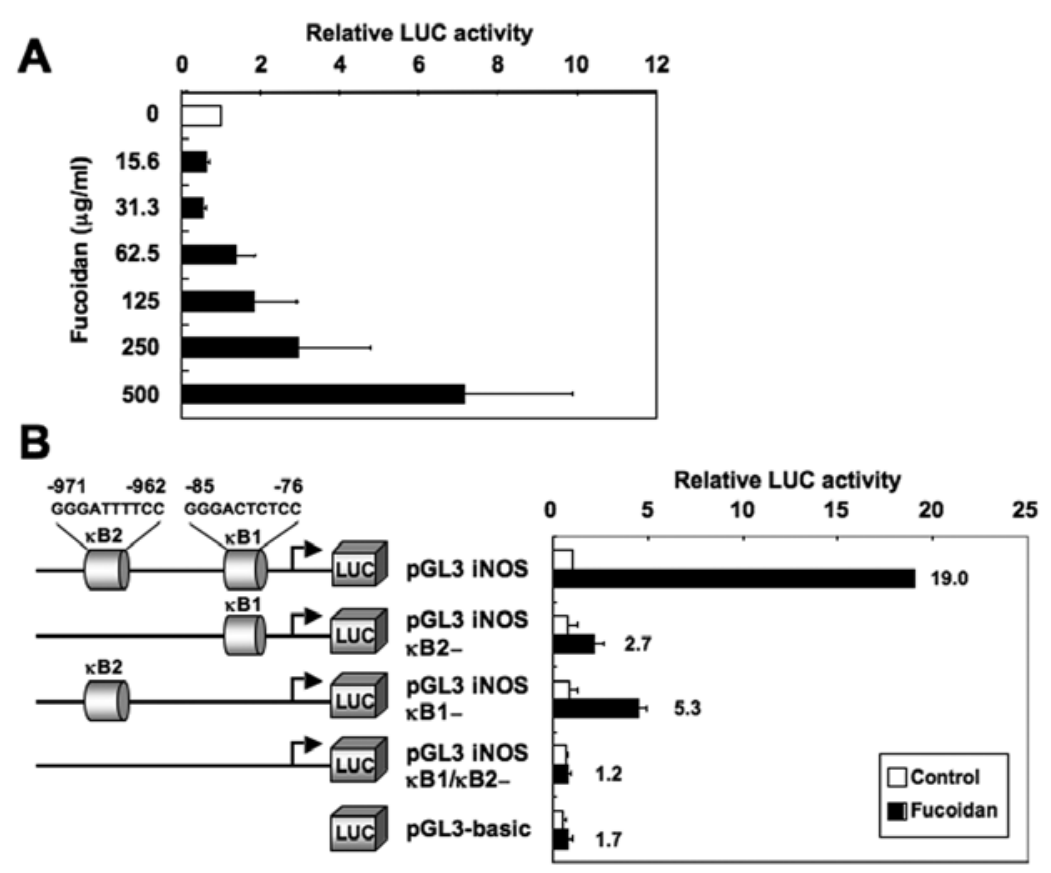

Figure 5. NF-kB sites in the murine iNOS promoter are essential for fucoidan responsiveness. (A) RAW264.7 cells were transfected with a murine iNOS promoter construct (pGL3 iNOS). Cells were treated with the indicated concentrations of fucoidan for $6 \mathrm{~h}$ and lysed for luciferase activity analysis. All values were calculated as the change (n-fold) in induction values relative to the basal level measured in untreated cells. (B) RAW264.7 cells were transfected with the indicated luciferase reporter plasmids. After transfection, the cells were left untreated or treated with fucoidan $(500 \mu \mathrm{g} / \mathrm{ml})$ for $6 \mathrm{~h}$, and the luciferase activities were measured. The activities are expressed relative to that of cells transfected with pGL3 iNOS without further treatment, which was defined as 1 . Luciferase activities were normalized based on the Renilla luciferase activity from phRL-TK. The numbers on the right side of the solid bars depict fold induction relative to the basal level measured in untreated cells. LUC, luciferase. Data are mean \pm SD of three independent experiments.

was determined simultaneously. Increasing amounts of NOR3 produced increasing amounts of nitrite in the culture medium (Fig. 4A, left panel), and there was a close relationship between the concentration of nitrite and the extent of cell growth inhibition in S-180 cells, as demonstrated by WST-8 assay (Fig. 4A, right panel).

To further evaluate the sensitivity of S-180 cells to the effect of NO, RAW264.7 cells were stimulated with fucoidan, and cocultivated with S-180 cells for $72 \mathrm{~h}$ in Transwell cultures. As demonstrated above, fucoidan inhibited S-180 cell growth during coculture with RAW264.7 cells (Fig. 4B, right panel). The addition of L-NAME, an inhibitor of NOS, to the medium decreased both the production of NO (Fig. 4B, left panel) and the suppression of S-180 cell growth (Fig. 4B, right panel). Data displayed in the two figures indicate a close relationship between NO production and S-180 cell growth inhibition by fucoidanstimulated RAW264.7 cells.

NF- $\boldsymbol{\kappa} B$ is necessary for fucoidan inducibility of iNOS promoter. To assess the effect of fucoidan on iNOS promoter activity, RAW264.7 cells were transfected with a murine iNOS-luciferase promoter/reporter construct and then incubated with various concentrations of fucoidan. The cells were lysed, and luciferase activity was measured. Fucoidan increased the expression of luciferase from the iNOS promoter in a dose-dependent manner (Fig. 5A). Expression of the iNOS gene in macrophages is regulated mainly at the transcriptional level, particularly by NF- $\kappa B$ (27). The murine iNOS promoter contains two putative NF- $\kappa$ B binding sites, one upstream (GGGATTTTCC, -971 to $-962 \mathrm{bp}$, designated NF- $\mathrm{kB} 2$ ) and one downstream
(GGGACTCTCC, -85 to $-76 \mathrm{bp}$, designated NF-кB1) (27). To test the relative contribution of the NF- $\kappa \mathrm{B}$ binding sites to the fucoidan-mediated activation of iNOS, we introduced a deletion into each or both sites. A single deletion of the $\mathrm{\kappa B} 2$ site markedly inhibited the fucoidan-mediated promoter activation, whereas a single deletion of the $\kappa \mathrm{B} 1$ site resulted in moderate activation. The combination of double deletions completely abolished the fucoidan-mediated promoter activation (Fig. 5B).

Fucoidan induces binding of $N F-\kappa B$ family proteins to two $N F-\kappa B$ sites. We next characterized the nuclear proteins in fucoidan-treated RAW264.7 cells that bind to sequences from the iNOS promoter in an NF- $\kappa B$-dependent manner. EMSA was performed with two probes; miNOS $\kappa \mathrm{B} 1$ and $\kappa \mathrm{B} 2$, oligonucleotides consisting of the NF- $\mathrm{\kappa B} 1$ and NF- $\kappa \mathrm{B} 2$ elements. Fucoidan induced, in a time-dependent manner, the appearance of nuclear proteins that bound to both probes in RAW264.7 cells (Fig. 6A). In both probes, the addition of excess of unlabeled $\kappa \mathrm{B} 1$ and $\kappa \mathrm{B} 2$ oligonucleotides to the binding reaction completely abolished the formation of the inducible DNA-protein complexes (Fig. 6B, lanes 2 and 9). In contrast, the formation of these DNA-protein complexes was not blocked by the addition of excess of unrelated oligonucleotide AP-1 (Fig. 6B, lanes 3 and 10). To identify the NF- $\kappa B$ family members that bind to the NF- $\kappa B$ motifs of the murine iNOS gene promoter, the binding reactions were preincubated with antibodies specific to p50, p65, c-Rel and p52. The anti-p50 antibody induced the supershifted bands and reduced the intensity of complexes $\kappa \mathrm{B} 1$ and $\kappa \mathrm{B} 2$ (Fig. $6 \mathrm{~B}$, lanes 4 and 11). The anti-p65 antibody blocked the formation of complexes $\kappa \mathrm{B} 1$ and $\kappa \mathrm{B} 2$ (Fig. 6B, lanes 5 and 12). The c-Rel 


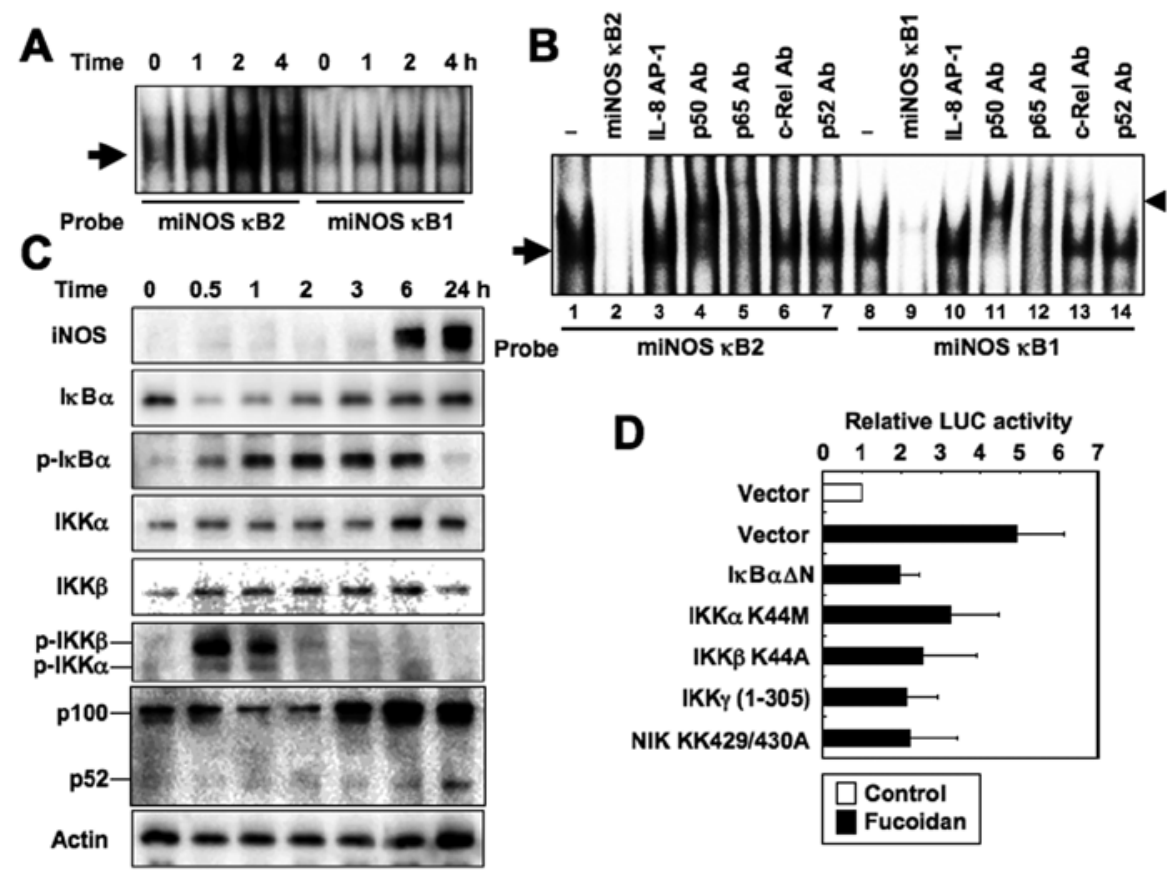

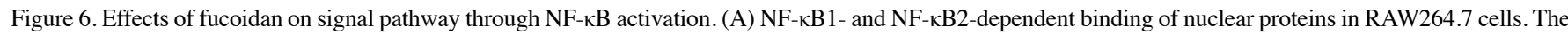
cells were treated with fucoidan $(250 \mu \mathrm{g} / \mathrm{ml})$ for the indicated time periods before preparing nuclear extracts for analysis by EMSA with probe miNOS $\kappa \mathrm{B} 1$ or $\mathrm{\kappa B} 2$. (B) Sequence specificity of NF- $\mathrm{kB}$ binding activity and characterization of proteins that bound to the NF- $\mathrm{KB}$ binding sites. Competition assays were performed with nuclear extracts from cells treated with fucoidan $(250 \mu \mathrm{g} / \mathrm{ml})$ for $2 \mathrm{~h}$. Excess amounts of competitor (100-fold) were added (lanes $2,3,9$ and 10$)$. A supershift assay in the same nuclear extracts was also performed. Antibodies (Ab) were added (lanes 4-7 and 11-14). Arrows indicate specific complexes, arrowhead indicates the DNA binding complexes supershifted. (C) Fucoidan activates NF- $\mathrm{kB}$, and consequently increases iNOS protein expression. Cells were treated with fucoidan (250 $\mu \mathrm{g} / \mathrm{ml})$ for the indicated time periods. Lysates were subjected to immunoblotting. (D) Overexpression of dominant negative mutants inhibits fucoidan-induced activation of the iNOS promoter. Cells were transfected with pGL3 iNOS and the mutant plasmids and then treated with fucoidan $(500 \mu \mathrm{g} / \mathrm{ml})$ for $6 \mathrm{~h}$. Open bar, luciferase activity of pGL3 iNOS and empty vector without treatment. All values were calculated as the change (n-fold) in induction values relative to the basal level measured in untreated cells. Data are mean \pm SD of three independent experiments.

antibody supershifted complex $\kappa \mathrm{B} 1$ (Fig. 6B, lane 13). These results indicate that the complexes $\kappa \mathrm{B} 1$ and $\kappa \mathrm{B} 2$ correspond to p50/p65/c-Rel and p50/p65, respectively.

Effects of fucoidan on signal pathway through $N F-\kappa B$ activation in RAW264.7 cells. We also examined whether fucoidan-mediated upregulation of iNOS gene expression involves signal transduction components in NF- $\mathrm{KB}$ activation. Activation of NF- $\kappa B$ requires the phosphorylation of two conserved serine residues of NF- $\mathrm{KB}$ inhibitory subunit, $\mathrm{I} \kappa \mathrm{B} \alpha$ (Ser32 and Ser36) within the N-terminal domain (28). Phosphorylation leads to the ubiquitination and 26S proteasome-mediated degradation of $\mathrm{I} \kappa \mathrm{B} \alpha$, thereby releasing NF- $\mathrm{KB}$ from the complex and its translocation to the nucleus and activation of various genes (28). To determine the role of IкB $\alpha$ phosphorylation and degradation in fucoidan-induced NF- $\mathrm{KB}$ translocation and activation, we investigated whether fucoidan induces phosphorylation and degradation of I $\mathrm{KB} \alpha$. The latter two processes were examined by Western blot analysis using antibodies against phosphorylated and total I $\mathrm{I} B \alpha$, respectively. Treatment of RAW264.7 cells with fucoidan resulted in phosphorylation and degradation of I $\mathrm{KB} \alpha$ within $30 \mathrm{~min}$ (Fig. 6C). Furthermore, fucoidan increased iNOS protein level in RAW264.7 cells within $6 \mathrm{~h}$.

$N F-\kappa B$ signal is essential for fucoidan-inducediNOS expression. To further confirm the involvement of I $\mathrm{B} \alpha$ phosphorylation and degradation, we transfected the cells with transdominant mutant of IкB $\alpha$ in which two critical serine residues required for inducer-mediated phosphorylation were deleted (17). Overexpression of mutant I $\mathrm{KB} \alpha$ inhibited the fucoidan-induced iNOS promoter activation (Fig. 6D), suggesting the involvement of I $\mathrm{KB} \alpha$ phosphorylation and degradation in fucoidan-induced iNOS expression.

NF- $\mathrm{KB}$ signaling occurs either through the classical or alternative pathway (29). In the classical pathway, NF- $\kappa \mathrm{B}$ dimers, such as $\mathrm{p} 50 / \mathrm{p} 65$, are maintained in the cytoplasm by interaction

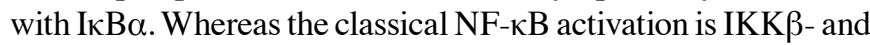
IKK $\gamma$-dependent and occurs through I $\mathrm{KB} \alpha$ phosphorylation and subsequent proteasomal degradation, the alternative pathway depends on activating NIK to stimulate IKK $\alpha$-induced phosphorylation and proteolytic processing of the p100 precursor protein to 552 (29). Indeed, fucoidan induced phosphorylation of IKK $\alpha$ and IKK $\beta$ within 30 min (Fig. 6C). Furthermore, the level of p52 protein increased in fucoidan-treated RAW264.7 cells (Fig. 6C). To address the mechanism of fucoidan-mediated iNOS expression, we investigated the role of NIK and IKK. Cotransfection with the dominant-negative mutant forms of NIK, IKK $\alpha$, IKK $\beta$ and IKK $\gamma$ inhibited fucoidan-induced iNOS expression (Fig. 6D). Taken together, these findings clearly demonstrate that fucoidan induces iNOS expression via activation of the $\mathrm{NF}-\kappa \mathrm{B}$ signaling pathway.

Because activation of the iNOS promoter by fucoidan required the activation of NF- $\mathrm{KB}$, we blocked NF- $\mathrm{KB}$ activation with Bay 11-7082, an inhibitor of IкB $\alpha$ phosphorylation (30) or LLnL, a proteasome inhibitor (31). Bay 11-7082 inhibited 


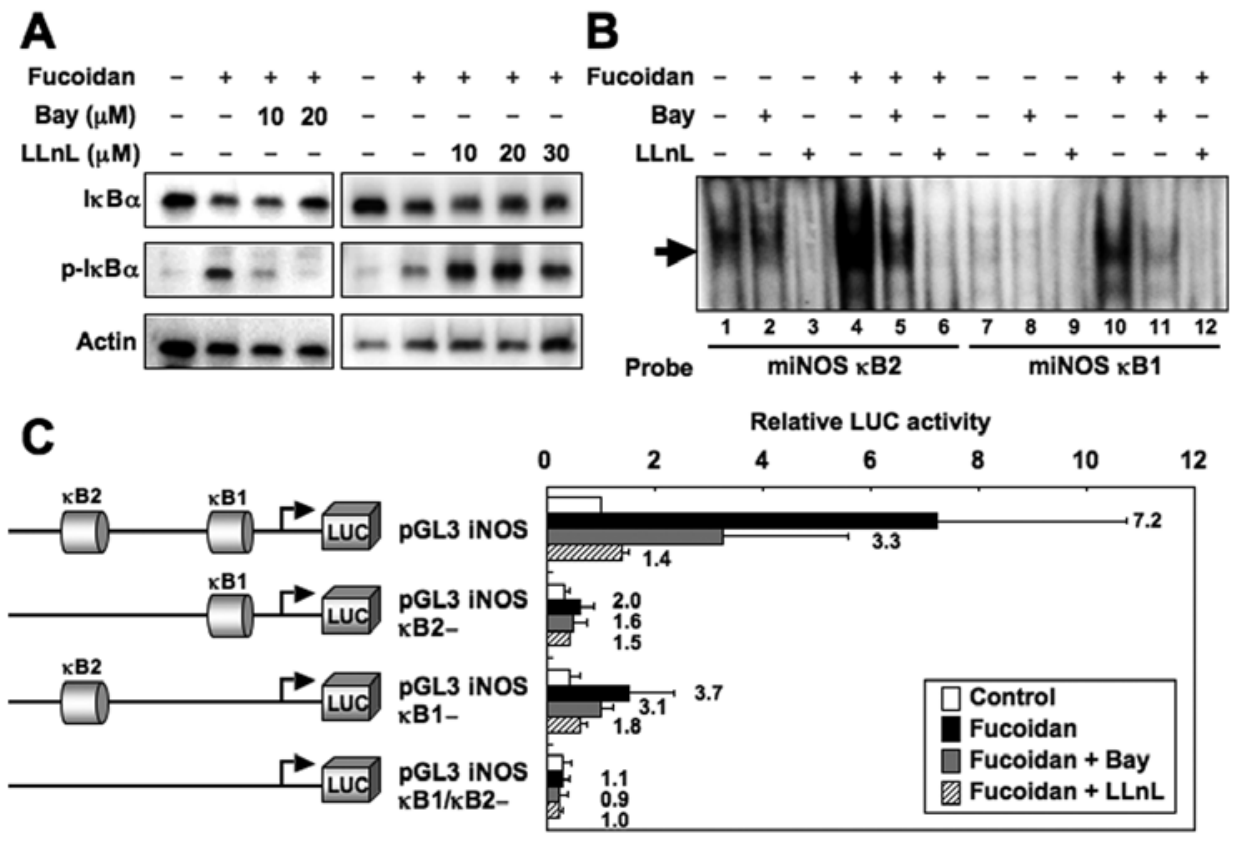

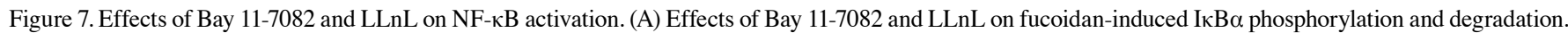
The phosphorylation and degradation of I $\mathrm{KB} \alpha$ was immunochemically assessed by treating cells preincubated with the indicated concentrations of Bay 11-7082 or LLnL for $1 \mathrm{~h}$ prior to fucoidan $(250 \mu \mathrm{g} / \mathrm{ml})$ treatment for $1 \mathrm{~h}$. (B) Effects of Bay 11-7082 and LLnL on NF-kB DNA binding activity. RAW264.7 cells were preincubated with or without Bay 11-7082 $(20 \mu \mathrm{M})$ and $\operatorname{LLnL}(30 \mu \mathrm{M})$ for $1 \mathrm{~h}$ prior to fucoidan treatment and subsequently treated with fucoidan $(250 \mu \mathrm{g} / \mathrm{ml})$ for $3 \mathrm{~h}$. Nuclear extracts from the harvested cells were analyzed for NF-кB. (C) iNOS reporter gene analysis. RAW264.7 cells were transfected with the indicated luciferase reporter plasmids. After transfection, cells were incubated in a medium containing Bay 11-7082 (20 $\mu \mathrm{M})$ or LLnL $(30 \mu \mathrm{M})$ for $1 \mathrm{~h}$ and then treated with fucoidan $(250 \mu \mathrm{g} / \mathrm{ml})$ for $6 \mathrm{~h}$. Thereafter, luciferase activities were measured. The activities are expressed relative to that of cells transfected with pGL3 iNOS without further treatment, which was defined as 1 . The numbers on the right side of the bars depict fold induction relative to the basal level measured in untreated cells. Data are mean \pm SD of three independent experiments.

A

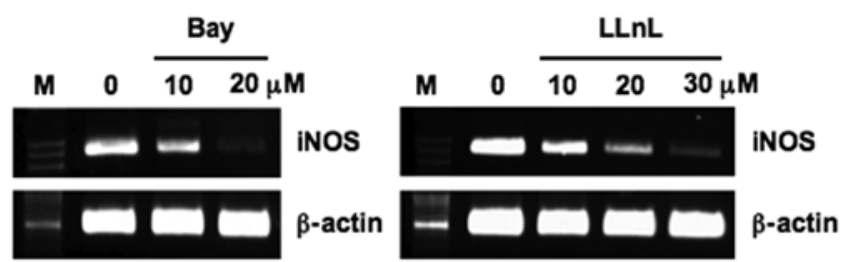

B

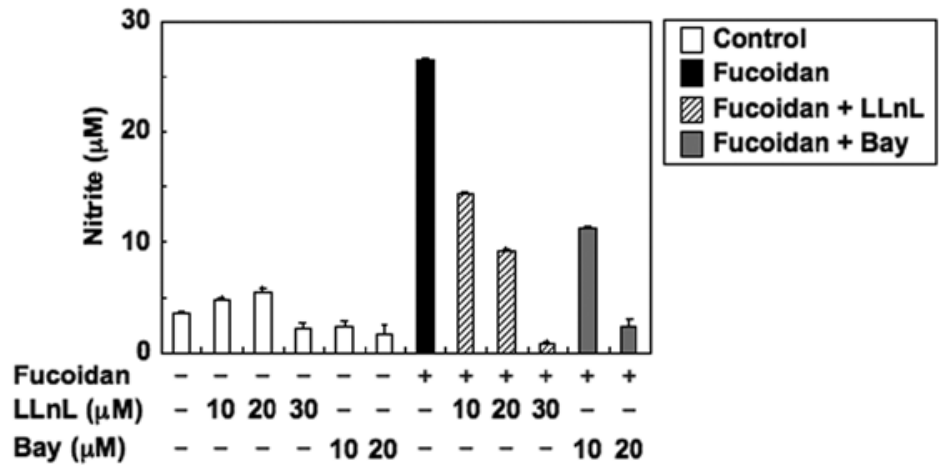

Figure 8. Effects of Bay 11-7082 and LLnL on fucoidan-induced iNOS mRNA expression and NO production in RAW264.7 cells. (A) RAW264.7 cells were pretreated with the indicated concentration of Bay 11-7082 or LLnL for $1 \mathrm{~h}$ before stimulation with fucoidan $(250 \mu \mathrm{g} / \mathrm{ml})$ for another $6 \mathrm{~h}$. The iNOS mRNA expression was determined by RT-PCR. (B) RAW264.7 cells were pretreated with the indicated concentration of Bay 11-7082 or LLnL for $1 \mathrm{~h}$ before stimulation with fucoidan $(250 \mu \mathrm{g} / \mathrm{ml})$ for another $72 \mathrm{~h}$. The nitrite content of culture media was analyzed. Data are mean \pm SD of triplicate cultures.

fucoidan-induced phosphorylation and degradation of IкB $\alpha$ (Fig. 7A, left panels). Furthermore, LLnL also prevented IкB $\alpha$ degradation, but not I $\kappa \mathrm{B} \alpha$ phosphorylation (Fig. 7A, right panels). Bay 11-7082 and LLnL markedly inhibited NF- $\mathrm{B}$ DNA binding (Fig. 7B, lanes 5, 6, 11 and 12). In addition, Bay 11-7082 and LLnL decreased fucoidan-induced iNOS promoter 
activity (Fig. 7C). Finally, Bay 11-7082 and LLnL resulted in a dose-dependent reduction in fucoidan-induced iNOS mRNA expression and NO production in RAW264.7 cells (Fig. 8).

\section{Discussion}

Previous in vitro and in vivo studies have demonstrated the anti-cancer properties of fucoidan, including the suppression of growth $(8,9,12,13)$, metastasis $(11,15)$, angiogenesis $(11,14)$, and the induction of apoptosis $(8,10,32)$ and autophagy (32) in a variety of cancer cells. In the present study, fucoidan was effective in inhibiting the growth of implanted S-180 cells, but this effect was not mirrored in the in vitro studies. One previous report suggested that the anti-tumor activity of fucoidan is related to the enhancement of immune responses (12). Interestingly, fucoidan-induced tumor regression did not require host T-cell participation since $\mathrm{S}-180$ cell tumors in nude mice regressed upon treatment. On the other hand, previous studies postulated that the macrophage-mediated cytotoxicity against some tumor cells was linked to NO $(23,25,26)$. The present results demonstrated that fucoidan alone could not inhibit S-180 cell growth in vitro. However, fucoidan-treated RAW264.7 cells inhibited S-180 cell growth. This anti-tumor activity correlated with NO production in activated RAW264.7 cells, and the addition of L-NAME, an inhibitor of NOS, inhibited, at least in part, the anti-tumor effect of fucoidan-treated RAW264.7 cells. The partial blockade of fucoidan by L-NAME suggests the possible effects of another yet unidentified soluble factor, in addition to $\mathrm{NO}$, that mediates the growth inhibitory effect of fucoidan. Thus, NO seems a significant component of the mechanism causing tumor regression. In this context, it should be emphasized that this experimental approach only allows the study of the effects mediated by soluble mediators. Other interactions involving direct contact between S-180 cells and neighboring macrophages will have additional effects on S-180 cells, modulating the proliferation and apoptosis of S-180 cells.

The other part of the present study investigated the molecular mechanism of fucoidan-induced NO production. The murine iNOS gene promoter contains several homologous consensus sequences for binding the transcription factors such as NF- $\mathrm{kB}$, AP-1 and Stat1 (33). The results highlighted the importance of

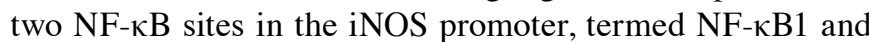
$\mathrm{NF}-\kappa \mathrm{B} 2$, to confer the effects of fucoidan on macrophages. Nuclear protein complexes that bind specifically to NF- $\kappa B 1$ and NF- $\mathrm{kB} 2$ after treatment of RAW264.7 cells with fucoidan contain p50/p65/c-Rel and p50/p65, respectively. In contrast, $\mathrm{NF}-\kappa \mathrm{B} 2$, but not NF- $\kappa \mathrm{B} 1$, is reported to confer induction by bacterial LPS (27). Fucoidan and LPS are well-defined ligands of the class A scavenger receptor and toll-like receptor 4, respectively $(34,35)$. These results indicate that the mechanism involved in the induction of iNOS expression by macrophage scavenger receptor is likely to be distinct from the mechanism involved in the induction of iNOS by toll-like receptor.

Bay 11-7082 and LLnL are relatively specific inhibitors of $\mathrm{NF}-\mathrm{\kappa B}$ activation $(30,31)$. Both agents blocked the production of nitrite, the expression of iNOS mRNA, the promoter activity of iNOS and the binding of NF- $\mathrm{kB}$ to NF- $\mathrm{kB} 1$ and $\kappa \mathrm{B} 2$ sites, indicating the likely involvement of NF- $\mathrm{kB}$ in the induction not just of iNOS-driven reporter constructs but of the iNOS gene itself in fucoidan-treated macrophages. Two previous studies reported that the interaction of macrophages with fucoidan enhances the production of $\mathrm{NO}(36,37)$. However, neither study tested the effect of fucoidan on the binding of NF- $\mathrm{\kappa B}$ proteins to the murine iNOS promoter. We found for the first time that the iNOS promoter activation induced by fucoidan was almost eliminated by the deletion of both NF- $\mathrm{KB}$ binding sites, even when the AP-1 sites were all conserved. Although the role of AP-1 in the fucoidan-induced NO production has been reported (36), the contribution of AP-1 site is not reasonable for the above result.

We confirmed the important role of NF- $\mathrm{kB}$ by showing that overexpression of dominant negative NIK, IKKs and I $\mathrm{B} \alpha$, potent inhibitors of NF- $\mathrm{KB}$ activation, inhibited fucoidan-induced activation of iNOS promoter. Furthermore, fucoidan induced p100 processing into p52 subunit, although supershift experiments did not demonstrate the involvement of p52 in NF- $\mathrm{kB}-\mathrm{DNA}$ binding complexes in fucoidan-treated RAW264.7 cells. Further studies are needed to explore the role of NIK-dependent alternative NF- $\kappa \mathrm{B}$ pathways in fucoidan-induced iNOS expression in macrophages.

Taken together, our data suggest that the regression of murine S-180 tumor by fucoidan involves NO-mediated growth inhibition by activated macrophages, and that fucoidan is a potentially useful anti-tumor agent for some cancers in humans.

\section{Acknowledgements}

We acknowledge Drs Dean W. Ballard, Romas Geleziunas and Kuan-Teh Jeang for providing the expression vectors for IкB $\alpha$-dominant-negative mutant; for NIK, IKK $\alpha$ and IKK $\beta$ dominant-negative mutants; and for IKK $\gamma$-dominant negative mutant.

\section{References}

1. Li B, Lu F, Wei X and Zhao R: Fucoidan: structure and bioactivity. Molecules 13: 1671-1695, 2008.

2. Shibata $H$, Iimuro $M$, Uchiya $N$, Kawamori $T$, Nagaoka $M$, Ueyama S, Hashimoto S, Yokokura T, Sugimura T and Wakabayashi K: Preventive effects of Cladosiphon fucoidan against Helicobacter pylori infection in Mongolian gerbils. Helicobacter 8: 59-65, 2003.

3. Hayashi K, Nakano T, Hashimoto M, Kanekiyo K and Hayashi T: Defensive effects of a fucoidan from brown alga Undaria pinnatifida against herpes simplex virus infection. Int Immunopharmacol 8: 109-116, 2008.

4. Cumashi A, Ushakova NA, Preobrazhenskaya ME, D'Incecco A, Piccoli A, Totani L, Tinari N, Morozevich GE, Berman AE, Bilan MI, Usov AI, Ustyuzhanina NE, Grachev AA, Sanderson CJ, Kelly M, Rabinovich GA, Iacobelli S, Nifantiev NE and Consorzio Interuniversitario Nazionale per la Bio-Oncologia, Italy: A comparative study of the anti-inflammatory, anticoagulant, antiangiogenic, and antiadhesive activities of nine different fucoidans from brown seaweeds. Glycobiology 17: 541-552, 2007.

5. Wang J, Zhang Q, Zhang Z and Li Z: Antioxidant activity of sulfated polysaccharide fractions extracted from Laminaria japonica. Int J Biol Macromol 42: 127-132, 2008.

6. Matsumoto S, Nagaoka M,Hara T,Kimura-Takagi I, Mistuyama K and Ueyama S: Fucoidan derived from Cladosiphon okamuranus Tokida ameliorates murine chronic colitis through the downregulation of interleukin- 6 production on colonic epithelial cells. Clin Exp Immunol 136: 432-439, 2004.

7. Choi EM, Kim AJ, Kim YO and Hwang JK: Immunomodulating activity of arabinogalactan and fucoidan in vitro. J Med Food 8: 446-453, 2005.

8. Fukahori S, Yano H,Akiba J, Ogasawara S, Momosaki S, Sanada S, Kuratomi K, Ishizaki Y, Moriya F, Yagi M and Kojiro M: Fucoidan, a major component of brown seaweed, prohibits the growth of human cancer cell lines in vitro. Mol Med Rep 1: 537-542, 2008. 
9. Riou D, Colliec-Jouault S, Pinczon du Sel D, Bosch S, Siavoshian S, Le Bert V, Tomasoni C, Sinquin C, Durand P and Roussakis C: Antitumor and antiproliferative effects of a fucan extracted from ascophyllum nodosum against a non-small-cell bronchopulmonary carcinoma line. Anticancer Res 16: 1213-1218, 1996.

10. Aisa Y, Miyakawa Y, Nakazato T, Shibata H, Saito K, Ikeda Y and Kizaki M: Fucoidan induces apoptosis of human HS-sultan cells accompanied by activation of caspase-3 and down-regulation of ERK pathways. Am J Hematol 78: 7-14, 2005.

11. Ye J, Li Y, Teruya K, Katakura Y, Ichikawa A, Eto H, Hosoi M, Hosoi M, Nishimoto S and Shirahata S: Enzyme-digested fucoidan extracts derived from seaweed Mozuku of Cladosiphon novae-caledoniae kylin inhibit invasion and angiogenesis of tumor cells. Cytotechnology 47: 117-126, 2005.

12. Itoh $\mathrm{H}$, Noda $\mathrm{H}$, Amano $\mathrm{H}$, Zhuaug $\mathrm{C}$, Mizuno $\mathrm{T}$ and Ito $\mathrm{H}$ : Antitumor activity and immunological properties of marine alga polysaccharides, especially fucoidan, prepared from Sargassum thunbergii of Phaeophyceae. Anticancer Res 13: 2045-2052, 1993.

13. Zhuang $\mathrm{C}$, Itoh $\mathrm{H}$, Mizuno $\mathrm{T}$ and Ito $\mathrm{H}$ : Antitumor active fucoidan from the brown seaweed, umitoranoo (Sargassum thunbergii). Biosci Biotechnol Biochem 59: 563-567, 1995.

14. Koyanagi S, Tanigawa N, Nakagawa H, Soeda $S$ and Shimeno $H$ Oversulfation of fucoidan enhances its anti-angiogenic and antitumor activities. Biochem Pharmacol 65: 173-179, 2003

15. Coombe DR, Parish CR, Ramshaw IA and Snowden JM Analysis of the inhibition of tumour metastasis by sulphated polysaccharides. Int J Cancer 39: 82-88, 1987.

16. Brandacher G, Winkler C, Schroecksnadel K, Margreiter R and Fuchs D: Antitumoral activity of interferon- $\gamma$ involved in impaired immune function in cancer patients. Curr Drug Metab 7: 599-612, 2006.

17. Brockman JA, Scherer DC, McKinsey TA, Hall SM, Qi X, Lee WY and Ballard DW: Coupling of a signal response domain in $\mathrm{I} \kappa \mathrm{B} \alpha$ to multiple pathways for NF- $\kappa \mathrm{B}$ activation. Mol Cell Biol 15: 2809-2818, 1995.

18. Geleziunas R, Ferrell S, Lin X, Mu Y, Cunningham ET Jr, Grant M, Connelly MA, Hambor JE, Marcu KB and Greene WC: Human T-cell leukemia virus type 1 Tax induction of NF- $\kappa \mathrm{B}$ involves activation of the I $\kappa \mathrm{B}$ kinase $\alpha(\mathrm{IKK} \alpha)$ and IKK $\beta$ cellular kinases. Mol Cell Biol 18: 5157-5165, 1998.

19. Iha H, Kibler KV, Yedavalli VRK, Peloponese J-M, Haller K, Miyazato A, Kasai T and Jeang K-T: Segregation of NF- $\kappa$ B activation through NEMO/IKK $\gamma$ by Tax and TNF $\alpha$ : implications for stimulus-specific interruption of oncogenic signaling. Oncogene 22: 8912-8923, 2003 .

20. Crosby MB, Svenson J, Gilkeson GS and Nowling TK: A novel PPAR response element in the murine iNOS promoter. Mol Immunol 42: 1303-1310, 2005.

21. Antalis TM and Goldbolt D: Isolation nuclei from hematopoietic cell types. Nucleic Acids Res 19: 4301, 1991.

22. Mori N and Prager D: Transactivation of the interleukin-1 $\alpha$ promoter by human T-cell leukemia virus type I and type II Tax proteins. Blood 87: 3410-3417, 1996.
23. Clancy RM and Abramson SB: Nitric oxide: a novel mediator of inflammation. Proc Soc Exp Biol Med 210: 93-101, 1995.

24. Koopman G, Reutelingsperger CPM, Kuijten GAM, Keehnen RMJ, Pals ST and van Oers MHJ: Annexin V for flow cytometric detection of phosphatidylserine expression on B cells undergoing apoptosis. Blood 84: 1415-1420, 1994

25. Sveinbjørnsson B, Olsen R, Seternes OM and Seljelid R: Macrophage cytotoxicity against murine Meth A sarcoma involves nitric oxidemediated apoptosis. Biochem Biophys Res Commun 223: 643-649, 1996.

26. Nathan $\mathrm{C}$ and $\mathrm{Xie} \mathrm{Q}-\mathrm{W}$ : Nitric oxide synthases: roles, tolls, and controls. Cell 78: 915-918, 1994.

27. Xie Q-W, Kashiwabara Y and Nathan C: Role of transcription factor $N F-\kappa B / R e l$ in induction of nitric oxide synthase. J Biol Chem 269: 4705-4708, 1994.

28. Karin M and Ben-Neriah Y: Phosphorylation meets ubiquitination: the control of NF- $\kappa$ B activity. Annu Rev Immunol 18: 621-663, 2000.

29. Dejardin E: The alternative NF- $\mathrm{kB}$ pathway from biochemistry to biology: pitfalls and promises for future drug development. Biochem Pharmacol 72: 1161-1179, 2006

30. Pierce JW, Schoenleber R, Jesmok G, Best J, Moore SA, Collins T and Gerritsen ME: Novel inhibitors of cytokine-induced $\mathrm{I} \kappa \mathrm{B} \alpha$ phosphorylation and endothelial cell adhesion molecule expression show anti-inflammatory effects in vivo. J Biol Chem 272: 21096-21103, 1997.

31. Jeremias I, Kupatt C, Baumann B, Herr I, Wirth T and Debatin KM: Inhibition of nuclear factor $\kappa \mathrm{B}$ activation attenuates apoptosis resistance in lymphoid cells. Blood 91: 4624-4631, 1998.

32. Park HS, Kim GY, Nam TJ, Deuk Kim N and Hyun Choi Y: Antiproliferative activity of fucoidan was associated with the induction of apoptosis and autophagy in AGS human gastric cancer cells. J Food Sci 76: T77-T83, 2011.

33. Xie Q-W, Whisnant R and Nathan C: Promoter of the mouse gene encoding calcium-independent nitric oxide synthase confers inducibility by interferon $\gamma$ and bacterial lipopolysaccharide. J Exp Med 177: 1779-1784, 1993.

34. Hsu H-Y, Hajjar DP, Khan KMF and Falcone DJ: Ligand binding to macrophage scavenger receptor-A induces urokinase-type plasminogen activator expression by a protein kinase-dependent signaling pathway. J Biol Chem 273: 1240-1246, 1998

35. Beitler BA: TLRs and innate immunity. Blood 113: 1399-1407, 2009.

36. Nakamura T, Suzuki H, Wada Y, Kodama T and Doi T: Fucoidan induces nitric oxide production via $\mathrm{p} 38$ mitogen-activated protein kinase and NF- $\kappa \mathrm{B}$-dependent signaling pathways through macrophage scavenger receptors. Biochem Biophys Res Commun 343: 286-294, 2006

37. Yang JW, Yoon SY, Oh SJ, Kim SK and Kang KW: Bifunctional effects of fucoidan on the expression of inducible nitric oxide synthase. Biochem Biophys Res Commun 346: 345-350, 2006. 